\title{
La Cartografía, ien manos de quién está? Las disputas institucionales por las prácticas de relevamiento en Argentina
}

Who owns cartography? Institutional disputes over survey practices in Argentina

\author{
Ana Gómez Pintus \\ agomezpintus@gmail.com \\ Instituto de Investigación en Historia, Teoría y Praxis \\ de la Arquitectura y la Ciudad (HiTePAC), Facultad \\ de Arquitectura y Urbanismo de la Universidad \\ Nacional de La Plata - CONICET, Argentina \\ Malena Mazzitelli Mastricchio \\ mastricchiomalena@gmail.com \\ Instituto de Investigación en Historia, Teoría y Praxis \\ de la Arquitectura y la Ciudad (HiTePAC), Facultad \\ de Arquitectura y Urbanismo de la Universidad \\ Nacional de La Plata - CONICET, Argentina
}

Recepción: 03 Junio 2020

Aprobación: 12 Agosto 2020

Publicación: 02 Noviembre 2020

\section{Cita sugerida: Gómez Pintus, A. y Mazzitelli}

Mastricchio, M. (2020). La Cartografía, ¿en manos de quién está? Las disputas institucionales por las prácticas de relevamiento en Argentina. Geograficando, 16(2), e080. https://doi.org/10.24215/2346898Xe080

\section{INTRODUCCIÓN}

¿Qué es una cartografía institucionalizada? ¿Qué es una institución cartográfica? Durante el siglo XIX coexistieron diferentes imágenes cartográficas del territorio nacional. Tal es así que en 1889 se estableció una normativa legal que desconocía todo carácter público de los mapas, incluso aquellas obras cartográficas que habían tenido el privilegio de contar con financiamiento estatal. Desde la sanción de esa norma es posible rastrear diferentes intentos que pretendieron moldear legalmente las imágenes del territorio (Mazzitelli Mastricchio y Lois, 2004). Este proceso, que habría tenido su origen a fines del siglo XIX, culminó con la 
sanción de la ley N. 12696 (conocida como la Ley de la Carta) sancionada en 1941. La sanción de la Ley otorgó a una institución militar, el Instituto Geográfico Militar (IGM), la potestad de fiscalizar la cartografía que se realizaba del territorio estatal. A partir de este hecho, se convirtió, al menos en el imaginario geográfico, en la única dependencia del Estado con autoridad cartográfica y su producción fue considerada, tanto dentro y fuera de la academia, como la "cartografía oficial del Estado".

Si bien es cierto que la Ley establece y autoriza esta supremacía cartográfica en manos del IGM, este dossier pretende demostrar que existieron y existen diferentes instituciones -tanto públicas como privadasque también se dedicaron a cartografiar el territorio en diferentes escalas. En este sentido los seis artículos que contiene este número intentan contribuir al campo de la historia de la cartografía ponderando ciertas prácticas de relevamiento, formas de visualización del terreno y lógicas de selección que existieron por fuera del (y en relación al) Instituto. Sostenemos que las producciones cartográficas de estas instituciones también circularon y se instalaron en diferentes ámbitos, de modo que favorecieron a la construcción de una espacialidad nacional y un saber técnico que se constituyó como un saber estatal (Plotkin y Zimmermann, 2012).

Por otro lado, se pretende demostrar que lejos de trabajar de manera aislada ambas instituciones - públicas y privadas- conocían las lógicas de trabajo: se comentaban y discutían entre pares, al igual que estaban al tanto de las nuevas prácticas topográficas tanto nacionales como internacionales.

Este dossier surgió del Simposio organizado por el Grupo de Estudios Cartografía e Historia Territorial con sede en el Instituto de Historia Teoría y Praxis de la Arquitectura y la Ciudad (HiTePAC), Facultad de Arquitectura y Urbanismo (FAU) de la Universidad Nacional de La Plata (UNLP), en diciembre de 2019. El mismo está dividido en tres partes: la primera destinada a visualizar la cartografía privada. Intentamos poner sobre el tapete prácticas de relevamiento propias de las cartografías comerciales. En esta sección, que llamamos Practicas y Saberes cartográficos privados: cartografías comerciales, incluimos el trabajo de Graciela Favelukes denominado "Licencias cartográficas, juegos de escala, fronteras difusas. La publicación de planos callejeros de una ciudad en expansión", donde la autora muestra cómo los cartógrafos se permitían ciertas "licencias cartográficas", como la que implica la alteración de la escala en pos de representar las prácticas cotidianas de la ciudad. Dicho de otra manera, Favelukes demuestra a partir de los mapas de Buenos Aires del siglo XIX que para representar la espacialidad de una ciudad es necesario alterar la representación del terreno. El segundo texto, de Ana Gómez Pintus y Florencia Minatta, "Mapas callejeros o cómo transitar el rea Metropolitana de Buenos Aires. La guía Filcar de planos suburbanos de 1955”, pone el foco en la cartografía privada Filcar para demostrar que constituye un dispositivo fundamental -nada ingenuo- a partir del cual se conoce el espacio bonaerense y se organiza la circulación de los sujetos a través del mismo, construyendo una espacialidad barrial propia de los partidos que conforman el conurbano.

La segunda sección de este dossier está pensada para las Prácticas y Saberes cartográficos del siglo XIX: Instituciones y actores. En este apartado contamos con los trabajos de Melisa Pesoa y Carla Lois, quienes desde diferentes objetos de estudio dan cuenta de la heterogeneidad de los actores e instituciones que trabajaron en la producción de la cartografía nacional. Así, Pesoa revisa una historia de larga duración. En "Un mapa para la provincia. La institucionalización del conocimiento cartográfico durante el siglo XIX en la Provincia de Buenos Aires", demuestra que la estandarización de los trabajos, la redacción de instrucciones, fueron las que, en suma, condujeron a una normalización de las prácticas que tuvieron su origen en el Estado rivadaviano y se prolongaron durante todo el siglo.

Corresponde señalar que los actores se amplían en los debates sobre políticas de fronteras como los que propone Carla Lois. "Teorías geográficas y técnicas cartográficas al servicio de la diplomacia: Hans Steffen, un geógrafo prusiano en los Andes australes”, despliega el recorrido del geógrafo -contratado por el gobierno Chileno- donde narra varios episodios entre los que se destacan los debates sobre las políticas de fronteras. 
Como es de esperar, las políticas cartográficas de las fronteras en la Argentina no solo tuvieron como actores a las instituciones locales sino también aquellas que desde las naciones limítrofes actuaban en simultáneo. La investigación ilumina las prácticas y los saberes chilenos en diálogo con las prácticas y los saberes que la Argentina puso en juego en el escenario de la contienda limítrofe Argentina-Chile sobre los Andes.

Por último, en el apartado de Prácticas y Saberes cartográficos del siglo XX: instituciones estatales, se reúne el análisis de las oficinas cartográficas que ya son parte constitutiva de los saberes estatales. Aquí contamos con las investigaciones de Malena Mazzitelli Mastricchio y Federico Amarilla. Ambos construyen su aporte en torno a instituciones del siglo XX que relevaron el territorio argentino. En este sentido el artículo de Mazzitelli Mastricchio, “¿De quién es la topografía? el plan cartográfico de la Dirección de Minas, Geología e Hidrología", propone analizar las prácticas de relevamiento de la Dirección y su posible contribución con la estandarización de la cartografía en el siglo XX. En sintonía con el trabajo de Pesoa, que demuestra la estandarización de los trabajos en el siglo XIX, Mazzitelli Mastricchio se concentra en el impacto que tuvo la Ley de la Carta en la visualización del terreno en la cartografía de la Dirección. Por último, en “Trabajos topográficos. Un acercamiento preliminar al armado del caleidoscopio topográfico nacional”, Federico Amarilla despliega una sistematización de instituciones estatales -nacionales y provinciales- que intervinieron topográficamente el territorio. Destaca que el IGM realiza un relevamiento homogéneo (tanto en escala como en las prácticas de visualización) a partir del cual selecciona áreas de "supuesto interés" en recursos naturales y sobre los que -una vez mapeados o definidos- actuaría la institución más acorde para su explotación. Para este autor, la cartografía resultante del IGM debe entenderse como una primera mirada sobre el terreno que luego será profundizada por una institución más específica.

En suma, la organización de los artículos tiene dos objetivos. Por un lado, pretende dar cuenta de cómo fue el proceso que llevó de la coexistencia de actores y de instituciones decimonónicas a la centralización del saber cartográfico en la esfera estatal; y por el otro demostrar que a pesar de esta centralización existen vínculos de conexión técnica entre las diferentes escales del Estado y el ámbito privado que nos permiten pensar a la cartografía como un saber colectivo y social.

\section{REFERENCIAS}

Mazzitelli Mastricchio, M. y Lois, C. (2004). "Pensar y representar el territorio: dispositivos legales que moldearon la representación oficial del territorio del Estado argentino en la primera mitad del siglo XX”. En https://ww w.naya.org

Plotkin, M. y Zimmermann, E. (Comp.) (2012). Los saberes del Estado. Buenos Aires: Edhasa. 